\title{
MODELO MATEMÁTICO DO COMPORTAMENTO DE PÉ DE UMA PRÓTESE PARA AMPUTADOS ABAIXO DO JOELHO
}

\author{
J. P. SILVA ${ }^{1 *}$, B. A. RODRIGUES ${ }^{1}$, J. C. S. CASADO ${ }^{2}$, S. K. CORREIA ${ }^{2}$, J. V. C. SILVA ${ }^{2}$, T. DIAS ${ }^{1}$ e S. S. R. F. ROSA ${ }^{1}$ \\ ${ }^{1}$ Universidade de Brasília \\ ${ }^{2}$ Universidade Federal de Alagoas \\ joziane.eng@gmail.com*
}

Artigo submetido em fevereiro/2016 e aceito em maio/2016

DOI: 10.15628/holos.2016.4191

\section{RESUMO}

O desenvolvimento de próteses antropomórficas é uma área de pesquisa que vem chamando a atenção dos centros de pesquisa no mundo inteiro. A aplicação de conhecimentos na área da robótica tem tornado estes dispositivos cada vez mais inteligentes. As próteses robóticas para membros inferiores possuem uma maior complexidade, pois elas podem influenciar substancialmente na postura e mobilidade de seu usuário. As ferramentas matemáticas empregadas no desenvolvimento de robôs podem ser aplicadas no modelamento de próteses e possuem grande importância para a implementação de seu controle. Este trabalho desenvolve um modelo matemático aplicado a uma prótese de pé robótico com 2 graus de liberdade. $\mathrm{O}$ algoritmo de Denavit-Hartenberg é uma ferramenta bastante eficaz na representação de sua cinemática de onde podem ser extraidas diversas relações que permitem relacionar orientação e posição. A orientação do pé com relação ao solo pode ser tomada por sensores de ultrassom. A marcha humana também é um grande fator no controle de uma prótese de pé robótico e pode ser analisada como critério de comportamento do pé.

PALAVRAS-CHAVE: Próteses Robóticas. Modelo Matemático. Marcha Humana. Cinemática.

\section{MATHEMATICAL MODEL OF FOOT BEHAVIOR OF AN IMPLANT TO BELOW THE KNEE AMPUTEES}

\begin{abstract}
The development of anthropomorphic prosthesis is an area of research that has attracted the attention of research centers worldwide. The application of knowledge in the robotics field has made increasingly intelligent devices. The robotic prostheses for lower limbs have a greater complexity because they can substantially influence the posture and mobility of its user. The mathematical tools used in the development of robots can be applied to the modeling of prosthesis and has great im-
\end{abstract}

portance for the implementation of their control. This paper develops a mathematical model applied to a robotic foot prosthesis with 2 degrees of freedom. The DenavitHartenberg algorithm is a very effective tool in a representation where kinematic can extract various relationships that allow relating orientation and position. Ultrasound sensors can make the orientation of the foot with relation the ground. The human gait is also a major factor in the control of a robotic foot prosthesis and can be analyzed as standing behavior criterion.

KEYWORDS: Robotic Prosthetics. Mathematical Model. Human Gait. Kinematics. 


\section{INTRODUÇÃO}

Desde a antiguidade, o homem procura substituir membros perdidos por dispositivos construídos de forma criativa (CASSEMIRO, 2002). Com o avanço da tecnologia nas mais diversas áreas do conhecimento, as próteses têm se tornado cada vez mais inteligentes e sofisticadas. Isso se deve principalmente ao desenvolvimento eletrônico, que possibilitou a elaboração de sistemas que permitem a interação de próteses robóticas com o ambiente. Com isso, o desenvolvimento de próteses robóticas antropomórficas tem sido objeto de estudo para os grandes centros de pesquisas do mundo.

À priori, a dedicação dos pesquisadores no estudo e desenvolvimento de próteses antropomórficas foi voltada para o de braços robóticos (BLAYA e HERR, 2004). Enquanto próteses de braço robótico podiam ser controladas com mais facilidade através da potência exercida pelo corpo ou captura de Sinais Eletromiográficos (EMG), as próteses para membros inferiores influem significativamente no movimento e na postura do usuário. Este tipo de dispositivo é objeto de estudo deste trabalho.

A robótica bípede é uma grande aliada no campo do desenvolvimento de próteses de membros inferiores. Isto porque muitos dos temas abordados para a implementação de robôs bípedes podem ser aplicados no desenvolvimento de dispositivos que visam auxiliar a locomoção de pessoas com deficiência. Muitas das ferramentas matemáticas empregadas para modelar robôs podem ser aplicadas em próteses e outros dispositivos auxiliares. Gomes (2009) utilizou o Zero Moment Point (ZMP) como critério para traçar trajetórias do padrão de marcha dos membros de uma órtese robótica. O mesmo critério é usado por Huang et al (1999), Park e Kim (1998) e Ferreira, Crisóstomo e Coimbra(2003) para o desenvolvimento de robôs bípedes.

Ferramentas matemáticas tem sido amplamente difundidas nos últimos anos, e sua utilização no ambiente industrial, contribui para melhorias no processo de produção de modo a evitar gastos excessivos de recursos e desperdícios de produção (WAVRZYNCZAK, 2016). A representação de Denavit-Hartenberg (representação D-H) é a principal ferramenta para modelar a cinemática de robôs. Esta representação segue um algoritmo bastante sistemático para relacionar um elemento terminal como um referencial fixo. Ela é muito utilizada para modelar manipuladores robóticos (CASSEMIRO, 2002; SANTOS, 2004). Esta representação é bastante eficiente para manipuladores robóticos com até 6 Graus de Liberdade (GL) (CASSEMIRO, 2002). Cascão et al (2005) aplicou esta ferramenta no modelo de uma prótese antropomórfica para amputados acima do joelho. Outra forma menos rigorosa é o uso de referenciais locais em cada junta do manipulador robótico. Alves (2009) simulou um pé em uma ferramenta de matemática computacional através deste método.

Um dos grandes desafios na elaboração de uma prótese para membros inferiores é traçar um modelo de comportamento do pé durante o caminhar. A grande variável para este tema é o tipo de "gait" humano executado. "Gait" é o termo usado para designar um ciclo de movimento das pernas de um animal ou robô (FERREIRA, CRISÓSTOMO e COIMBRA, 2003). Assim, não se pode traçar um padrão único de movimentos, mas é possível encontrar relações entre cada forma de "gait" através da biomecânica do movimento. Popovic e Englehart (2004) investigaram que os momentos angulares primitivos com seus respectivos gaits normalizados dependentes possuem suas distribuições invariantes com a velocidade. Para modelar o comportamento de um pé, Brasil (2008) assumiu que a sola do pé e o solo poderiam ser interpretados como dois planos quaisquer, assim, projetou pontos distintos do pé no solo para a obtenção de suas distâncias e dos ângulos do plano da sola.

Outra variante para traçar modelos de comportamento do pé é a topologia do solo. $O$ tipo de terreno tem bastante influência sobre o gait. Jin et al (2000) propuseram que a identificação do solo poderia 
ser feita através da análise de EMG que são usados no controle do momento resistivo de próteses para amputados acima do joelho.

O estudo das características antropomórficas do pé humano também tem fundamental importância para elaborar e implementar próteses para membros inferiores. Rosa et al (2014) mostra que uma análise dinâmica usando um modelo matemático de controle junto com técnicas como a integração numérica, o deslocamento histórico, velocidade, aceleração, retrato de fase, a bacia de atração e bifurcação diagrama é apresentado mostram que a pressão em determinados pontos da região plantar causam ulcerações. Para Borges Filho e Almeida (2004), o pé humano possui características únicas, e que tornam este membro um traço marcante nos seres humanos.

Este trabalho tem como objetivo a modelagem matemática de uma prótese antropomórfica de pé robótico. Serão abordados conceitos relacionados à modelagem cinemática, dinâmica do caminhar, orientação espacial do pé e estudo da marcha humana. Também será apresentado um protótipo e um modelo para a prótese a ser implementada.

\section{CARACTERÍSTICAS ANTROPOMÓRFICAS DA MARCHA E DO PÉ}

\subsection{Locomoção Humana}

Entre os mamíferos, o modo de locomoção terrestre bípede a passos largos é único da linha evolutiva humana e pode ter sido a mudança chave que tornou possível a evolução de outras características distintamente humanas (BORGES FILHO e ALMEIDA, 2004).

Durante a locomoção há uma série de forças atuando no corpo. A sola do pé é a região que sofre a força de reação do solo no período de contato. A Figura 1 mostra o comportamento da força que se aplica no solo durante este contato.

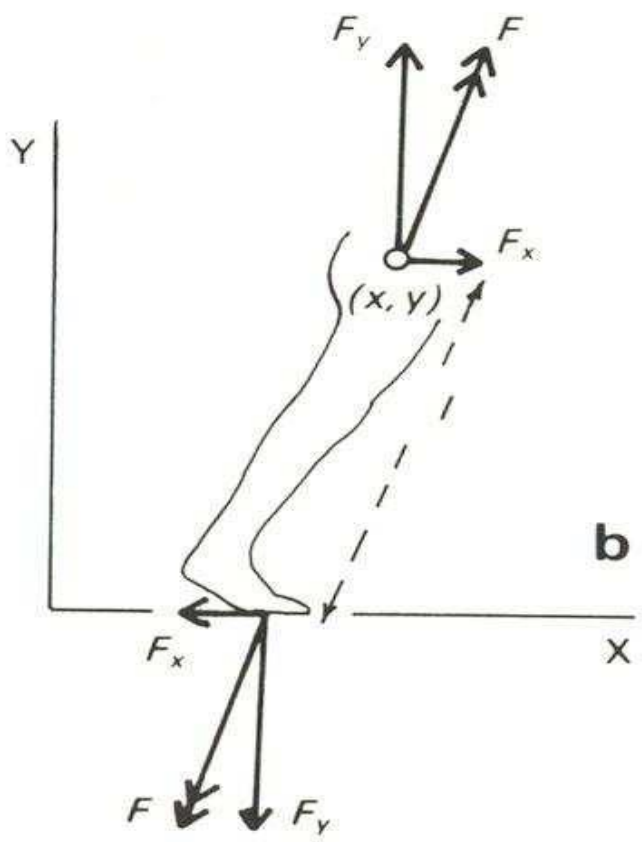

Figura 1: Força aplicada ao solo e suas componentes. Fonte: (NADALIN, 2010).

Esta força foi medida em experimentos através de dinamômetros adaptados em uma plataforma móvel. A Figura 2 apresenta as componentes $\mathrm{x}$ e y desta força durante o ciclo de caminhar de uma pessoa andando devagar, andando rápido e correndo. 

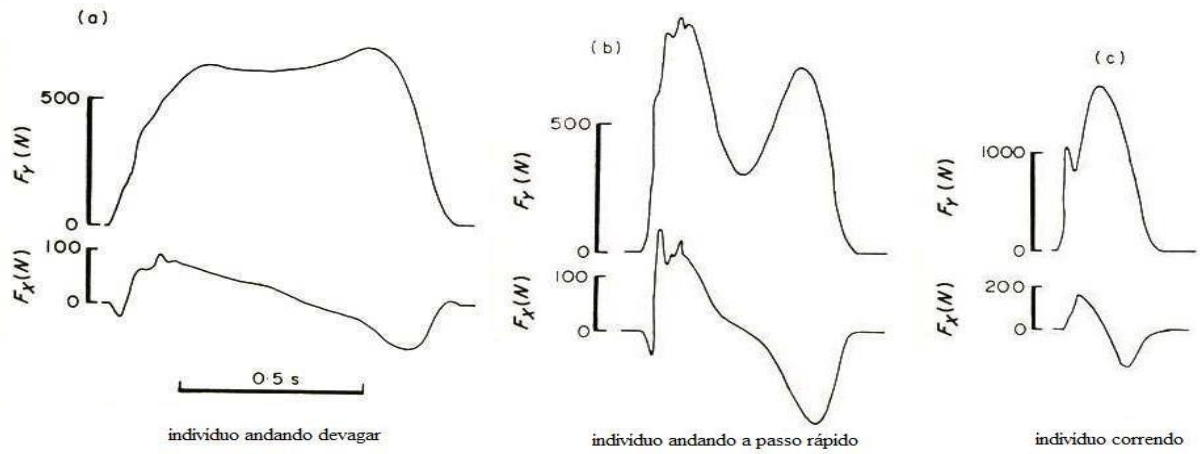

Figura 2: Comportamento das componentes da força aplicada ao solo durante um ciclo de marcha lenta (à esquerda), rápida (ao meio) e correndo (à direita). Fonte: (NADALIN, 2010)

Analisando os dados apresentados pela Figura 2, pode-se concluir que a queda da intensidade da força no meio do período das amostragens se deve pelo fato de que neste momento, no início do contato com o solo, o pé exerce uma força que resulta da força peso do corpo com a força do impulso tomado para movimentar o corpo. No final do contato, o pé provoca uma força de impulso para deslocar o corpo novamente.

\subsection{Características do Pé Humano}

O pé é considerado a parte mais tipicamente humana da anatomia do homem, constituindo o sinal principal e distinto que separa o homem de outros animais (locomoção humana). A sola do pé tem a característica de se adaptar a tipologia do solo de modo a permitir o melhor apoio ao corpo durante o caminhar.

Pisar sobre uma superfície estimula os receptores de pressão situados nas plantas dos pés, causando uma contração reflexa dos membros extensores. Isto é conhecido como reflexo de contração dos extensores cuja utilidade é evidente na locomoção e postura ereta, contribuindo para a manutenção desta. Na posição ereta, o peso distribui-se uniformemente entre o dorso do pé e o calcanhar. Sob a tensão de sustentação de peso, o pé se alonga e se alarga ligeiramente. $O$ pé possui dois apoios: 0 apoio calcâneo e 0 apoio frontal da região proximal aos dedos.

A Figura 3 mostra como ficam os ossos do pé no final do contato com o solo. Ao tocar o solo, a força exercida pelo peso corporal chega ao seu valor máximo no calcanhar conforme o outro pé deixa o solo. À medida que a região de apoio do pé aumenta, a força aplicada sobre ele permanece constante. Quando a região de apoio diminui a pressão do contato vai para o apoio frontal.

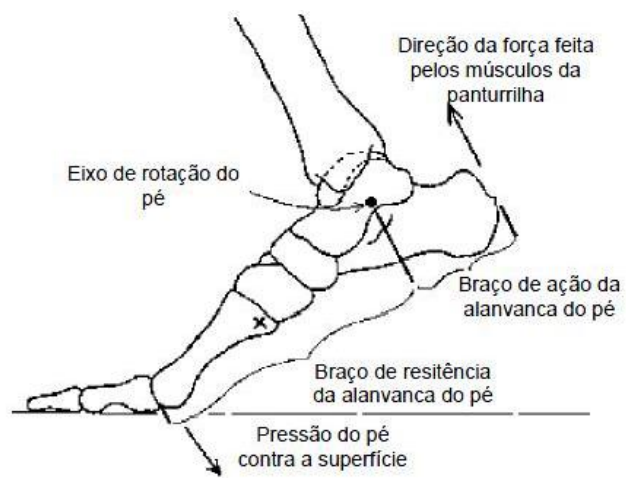

Figura 3: Ossos do pé no final do contato com o solo. Fonte: (NADALIN, 2010).

O pé humano pode executar dois tipos de movimentos fundamentais os de eversão/inversão e os de plantificação/dorsificação (BRASIL, 2009). Estes movimentos garantem ao pé dois graus de liberdade que Ihe permite atuar esfericamente em sua junta. 


\section{MATERIAIS E MÉTODOS}

\subsection{Modelo cinemático}

Existem diversos métodos para se obter o modelo cinemático de um sistema. Na robótica industrial, existem dois métodos muito utilizados: o método de vetores locais e a representação de Denavit-Hartenberg (D-H). Para este trabalho, optou-se pela representação D-H por motivo de convenção sistemática e pela facilidade de usá-lo. Para o caso de um sistema mais complexo é recomendado o uso de vetores locais (CASSEMIRO, 2002).

O modelo cinemático se divide em três tópicos: Cinemática direta, cinemática inversa e cinemática diferencial.

\subsubsection{Cinemática direta}

A cinemática direta preocupa-se em traçar a posição de um membro terminal com respeito a um sistema de coordenadas inicial em função dos $n$ ângulos das $m$ juntas. Este trabalho assume que a prótese robótica pé que é proposta possua dois Graus de Liberdade (GL's). A Figura 4 mostra um desenho CAD simplificado da prótese proposta.

A metodologia proposta para modelar os movimentos da prótese no espaço foi a representação de D-H (CASSEMIRO, 2002; CRAIG, 2005). Este método se apoia em 4 parâmetros chamados de , $l$ e $d$. A Tabela 1 mostra o valor dos parâmetros adotados nos 2 GL's da prótese.

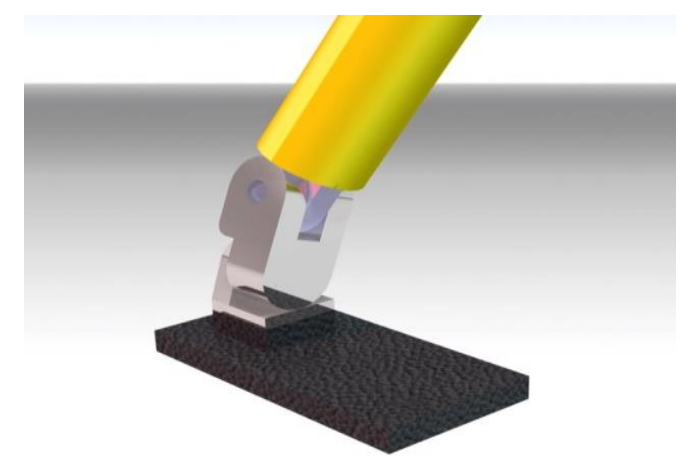

Figura 4: Simplificação de uma prótese com 2 GL's

Tabela 1: Parâmetro D-H da prótese robótica.

\begin{tabular}{ccccc}
\hline Elo & $\theta_{i}$ & $\alpha_{i}$ & $l_{i}$ & $d_{i}$ \\
\hline $\mathbf{1}$ & $\theta_{1}$ & 90 o & 0 & 0 \\
$\mathbf{2}$ & $\theta_{2}$ & 0 & $l$ & 0 \\
\hline
\end{tabular}

Em que $\theta_{i}$ é o ângulo de cada um dos i-ésimos elos, $\alpha_{i}$ é o ângulo de torção de uma junta a outra, $l_{i}$ é o comprimento entre cada junta e $d_{i}$ é o comprimento ao longo do eixo da junta.

Substituindo estes parâmetros na matriz de transformação homogênea ${ }^{i-1} T_{i}$ pode-se obter a matriz de transformação geral da prótese de pé robótico denotado pela Equação (1), formada pelas Equações (2), (3) e (4)Erro! Indicador não definido.. A Figura 5 mostra a representação geométrica dos elos analisados para se obter os parâmetros de Denavit-Hartenberg. 


$$
\begin{aligned}
& T_{2}^{0}=\left[\begin{array}{cc}
R_{2}^{0} & \bar{p}_{2}^{0} \\
\overline{0} & 1
\end{array}\right] \\
& R_{2}^{0}=\left[\begin{array}{ccc}
\cos \theta_{1} \cos \theta_{2} & -\cos \theta_{1} \sin \theta_{2} & \sin \theta_{1} \\
\sin \theta_{1} \cos \theta_{2} & -\sin \theta_{1} \sin \theta_{2} & -\cos \theta_{1} \\
\sin \theta_{2} & \cos \theta_{2} & 0
\end{array}\right] \\
& \bar{p}_{2}^{0}=\left[\begin{array}{c}
l \cos \theta_{1} \cos \theta_{2} \\
l \sin \theta_{1} \cos \theta_{2} \\
l \sin \theta_{2}
\end{array}\right] \\
& \overline{0}=\left[\begin{array}{lll}
0 & 0 & 0
\end{array}\right]
\end{aligned}
$$

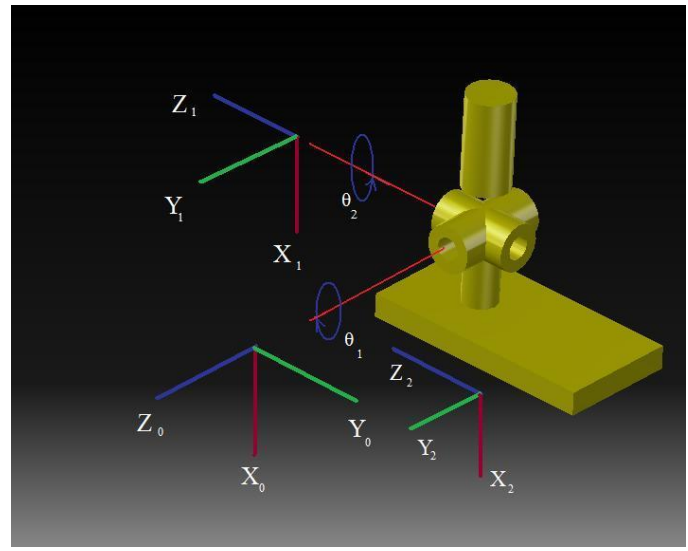

Figura 5: Representação geométrica dos elos analisados para se obter os parâmetros de Denavit-Hartenberg.

\subsubsection{Cinemática Inversa}

A cinemática direta resulta em expressões que descrevem o movimento da prótese robótica, entretanto é interessante saber quais valores de $\theta_{i}$ devem ser usados de maneira a posicionar o pé em determinado ponto do espaço. Assim, se percebe a necessidade de se obter relações entre o espaço cartesiano e o espaço das juntas.

A relação entre o espaço cartesiano e o espaço das juntas pode ser obtido através da matriz que denota o sentido e a posição no espaço descritos pela Equação (5). Desenvolver as relações entre a cinemática direta e a inversa nem sempre pode gerar uma solução. Mas devido à configuração dos graus de liberdade da prótese, foi possível chegar às Equações (6) e (7).

$$
\begin{aligned}
& {\left[\begin{array}{cccc}
\bar{n} & \bar{s} & \bar{a} & \bar{p} \\
0 & 0 & 0 & 1
\end{array}\right]} \\
& \theta_{1}=\tan ^{-1}\left(\frac{p_{y}}{p_{x}}\right) \\
& \theta_{2}=\tan ^{-1}\left(\frac{n_{z}}{s_{z}}\right)
\end{aligned}
$$

Observe que nas Equações (6) e (7) foi usada a função inversa da tangente para se obter os ângulos do espaço das juntas. Este tipo de função figura uma menor imprecisão numérica comparada com as funções seno e cosseno (SANTOS, 2004) sendo, portanto, mais eficiente para ser empregada. 


\subsubsection{Cinemática Diferencial}

A cinemática diferencial procura relacionar as variações angulares com as lineares da prótese. A matriz jacobiana mostra-se útil no intuito de se obter uma relação entre as velocidades de seu espaço operacional ou cartesiano com as velocidades do espaço das juntas. Sua obtenção pode ser feita de maneira analítica através dos incrementos sofridos por uma determinada trajetória conforme a Figura 6.

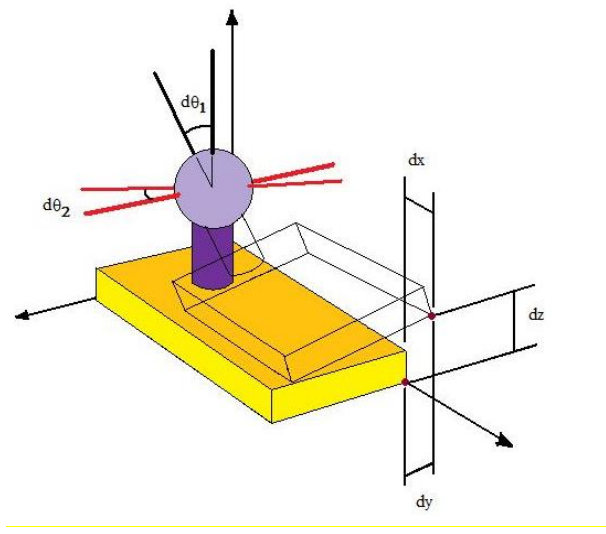

Figura 6: Representação dos incrementos lineares e angulares na prótese.

Para obter o jacobiano do pé robótico com 2 GL's deve-se calcular as derivadas parciais e obter a diferencial total do vetor posição do extremo da prótese onde sua trajetória é descrita através da Equação (1) pelo vetor $\bar{p}_{2}^{0}$. Dessa forma, se obtém o gradiente dos movimentos que a prótese poderá realizar no espaço operacional. O resultado do processo de derivação resulta na Equação (8).

$$
d \bar{p}=J \cdot d \bar{q}
$$

A partir da jacobiana da prótese é possível obter os incrementos a serem adicionados ao vetor posição do pé a partir dos incrementos angulares. Entretanto, se deseja obter um conjunto de coordenadas de incrementos angulares a partir de uma função cartesiana da trajetória desta prótese cujos incrementos são definidos por $d \bar{p}$. Assim, o vetor $d \bar{q}$ de incrementos angulares pode ser obtido pela Equação (9).

$$
d q=J^{-} \cdot d \bar{p}
$$

Onde $J^{-}$é o inverso da matriz jacobiana da prótese. Como $J$ é uma matriz quadrada do tipo $3 \times 2$ não é possível inverte-la pelos métodos convencionais, sendo necessário recorrer ao uso da psudoinversa de uma matriz, que neste caso é denominada $J^{+}$(ANTON e RORRES, 2001). Pela configuração deste caso, podese encontrar sua inversa pela Equação (10).

$$
J^{+}=\left(J^{T} J\right) \cdot J^{T}
$$

Uma vez obtido este vetor, pode-se controlar a prótese através de incrementos que podem satisfazer as Equações (11) e (12) e adicionar os incrementos através da Equação (13) que se trata de uma aproximação pela da série de Taylor (LEITHOLD, 1994).

$$
\begin{aligned}
& \lim _{\theta \rightarrow d \theta} \sin \theta=0 \\
& \lim _{\theta \rightarrow d \theta} \sin \theta=0 \\
& \bar{P}_{l}=\bar{P}_{i-1}+J \cdot d \bar{q}
\end{aligned}
$$




\subsection{Modelo Dinâmico}

\subsubsection{O ZMP critério de estabilidade}

Um critério que é usado com bastante frequência para controlar a marcha de robôs bípedes é o ponto de momento nulo ou Zero Moment Point (ZPM). Em Ferreira, Crisóstomo e Coimbra (2003), o ZMP é definido como o ponto no solo onde a soma de todos os momentos de força é nula. A Figura 7 mostra o ZMP de um robô estático.

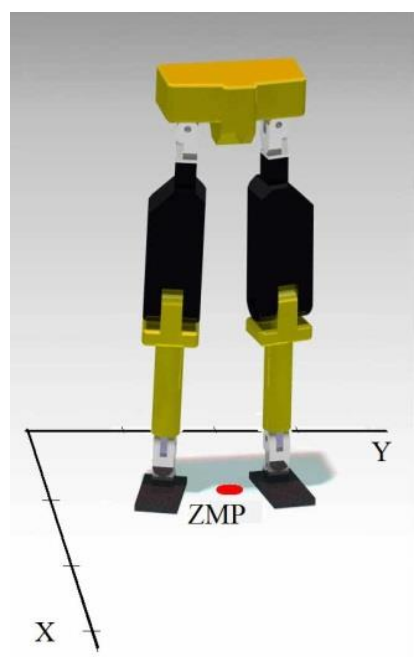

Figura 7: ZMP de um robô bípede.

Existe uma região estável que pode ser denominada como margem de estabilidade e que a distância do ZMP (Figura 8) à fronteira desta região é usada como um indicador de qualidade para este critério (HUANG et al, 1999). Se o ZMP estiver dentro do polígono de contato (PARK e KIM, 1998; FERREIRA, CRISTOMO e COIMBRA, 2003), diz-se que o robô está estável. O grau de estabilidade aumenta quando a menor distância entre o ponto e a fronteira é máxima. O ZMP pode ser obtido através das Equações (14) e (15) na qual resultam nas componentes das coordenadas do plano $(x, y)$ onde se projeta o ponto.

$$
\begin{gathered}
x_{\text {zmp }}=\frac{\sum_{i=1}^{n} m_{i} g x_{i}}{\sum_{i=1}^{n} m_{i} g} \\
y_{\text {zmp }}=\frac{\sum_{i=1}^{n} m_{i} g y_{i}}{\sum_{i=1}^{n} m_{i} g}
\end{gathered}
$$

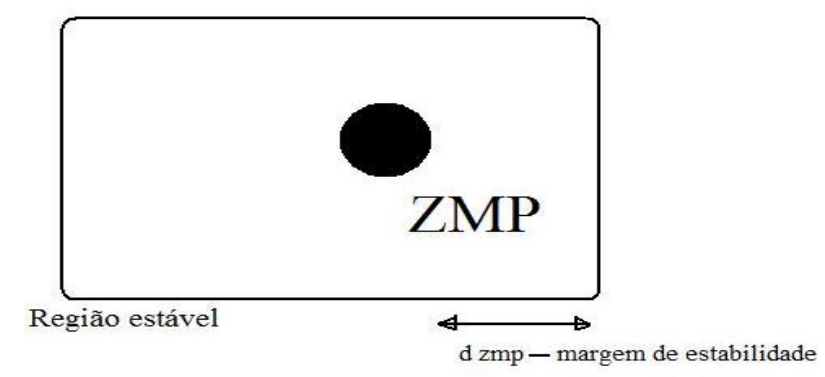

Figura 8: Polígono de estabilidade do ZMP.

Estas equações contemplam apenas o momento causado pelo peso dos vários membros do bípede, entretanto despreza os efeitos da aceleração linear e angular. Assim, elas se aplicam a um bípede estático. Para um corpo dinâmico, as Equações (16) e (17) consideram o momento causado pela translação e rotação de cada corpo. 


$$
\begin{aligned}
x_{z m p} & =\frac{\sum_{i=1}^{n} m_{i}(\ddot{z}+g) x_{i}-\sum_{i=1}^{n} m_{i} \ddot{x} z_{i}-\sum_{i=1}^{n} I_{i y} \alpha_{i y}}{\sum_{i=1}^{n} m_{i} g} \\
y_{z m p} & =\frac{\sum_{i=1}^{n} m_{i}(\ddot{z}+g) y_{i}-\sum_{i=1}^{n} m_{i} \ddot{y} z_{i}-\sum_{i=1}^{n} I_{i x} \alpha_{i x}}{\sum_{i=1}^{n} m_{i} g}
\end{aligned}
$$

Em que $m_{i}$ é a massa do i-ésimo elemento do bípede, $\ddot{x}, \ddot{y}, \ddot{z}$ são as acelerações lineares, $a_{i y} e a_{i x}$ são as acelerações angulares do i-ésimos elementos, $I_{i y} e I_{i x}$ são as inercias dos i-ésimos elementos, g é a aceleração gravitacional e $\mathrm{n}$ é o último elemento do bípede.

Apesar de ser bastante utilizado, o ZMP possui alguns defeitos como, por exemplo, de o caminhar baseado nele tende a ser vinte vezes mais dispendioso que o caminhar humano. Isso por que o ser humano consegue aproveitar melhor a energia cinética e potencial durante o caminhar (HEINEN e OSÓRIO, 2001). Entretanto, em Hirukawa et al (2006) uma vantagem vista no ZMP é a facilidade para traçar o ponto num plano horizontal.

\subsubsection{ZMP e a Força Aplicada ao Solo}

Estaticamente, uma pessoa ou qualquer sistema de locomoção bípede, ou outros tipos de sistemas de locomoção, tem seu peso dividido por entre os membros que estão em fase de apoio conforme. Assim, a força que atua em cada um dos membros, na mesma direção da força peso, satisfaz a igualdade na Equação (18).

$$
F_{P}=\sum_{i=1}^{n} F_{i}
$$

Em que $F_{i}$ é a força aplicada no i-ésimo membro, $n$ é o número de membros em apoio e $F_{P}$ é a força peso do indivíduo. Caso a igualdade da Equação (18) não seja satisfeita, podemos dizer que o ZMP do sistema não está no polígono de contato, podendo caracterizar um momento de instabilidade do bípede. A partir da equação anterior podemos estabelecer um critério de qualidade de estabilidade do bípede dado por (19), onde $0 \leq k \leq 1$.

$$
\frac{F_{i}}{F_{P}}=k
$$

Mas durante o ciclo de caminhar, para se manter estável é necessário observar a relação entre a força aplicada no solo pela perna no início da fase de apoio e com a força que a mesma atua sobre o solo no final de sua fase de apoio. A Figura 9 mostra a ação das duas forças. 


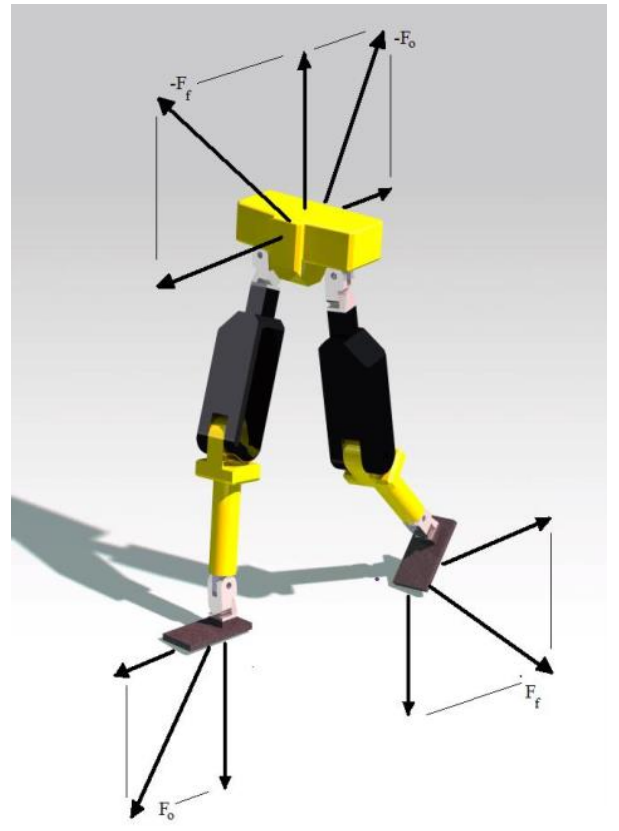

Figura 9: Forças atuantes durante o caminhar.

Visto que, durante o ciclo de caminhar depende da relação entre $F_{o}$ e $F_{f}$ denota um deslocamento do ZMP que pode ser interpretado da seguinte forma:

1. Se $F_{o}<F_{f}$, o ZMP é deslocado para um ponto mais a frente do seu atual ponto relativo;

2. Se $F_{o}>F_{f}$, o ZMP é deslocado para um ponto mais atrás do seu atual ponto relativo;

3. Se $F_{o}=F_{f}$, o ZMP é mantido em equilibrio na mesma posição relativa.

Como critério de qualidade de equilíbrio no plano frontal, a relação que podemos tomar para avaliar a estabilidade do ZMP no polígono de contato é satisfeita pela relação dada na Equação (20).

$$
0 \leq \frac{F_{f}}{F_{o}+F_{f}} \leq 1
$$

Note que, na Equação (19), quando o corpo está com equilíbrio elevado, k se aproxima de 0.5, pois nesse momento, a força tende a se dividir igualmente entre os membros em contato com o solo. No caso da Equação (20), quando esta relação atinge 0.5, pode-se dizer que o ZMP está numa região de alta estabilidade dinâmica, pois o intervalo entre 0 e 1 pode ser tratado como um espaço unitário limitado pela distância entre os pés.

\subsection{Modelo De Pêndulo Invertido}

O pêndulo pode ser usado para analisar a força que um bípede aplica sobre o solo e pode ajudar a compreender as relações entre o ZMP e esta força. Este modelo consiste no método do pendulo duplo que relaciona a aceleração da perna que não está em contato com a aceleração na qual o corpo é submetido durante o caminhar.

Para obter este modelo, assume-se que a perna que não está em contato com o solo pode ser analisada como um pêndulo normal, entretanto a outra perna é tomada como um pêndulo invertido, pois a massa deste pêndulo é a massa do bípede. A Figura 10 apresenta a configuração do bípede e a representação do sistema em questão. 

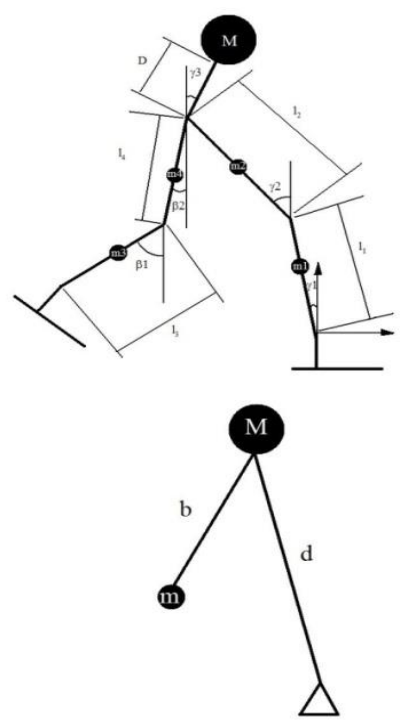

Figura 10: Configuração do bípede deste modelo (acima) e representação de pêndulo invertido (abaixo).

A massa em que a aceleração resultante será submetida é a soma das massas de todos os membros e também é a massa do pêndulo invertido. Esta massa pode ser concentrada em um único ponto que pode ser encontrado nas Equações (21) e (22). No caso do pêndulo comum, a massa é dada pela soma das massas de todos os elementos da perna e o comprimento deste pêndulo é a distância entre o centro de massa da perna até o centro de massa do corpo do bípede.

$$
\begin{gathered}
C M_{x}=\frac{\sum_{i=1}^{n} m_{i} x_{i}}{\sum_{i=1}^{n} m_{i}} \\
C M_{y}=\frac{\sum_{i=1}^{n} m_{i} y_{i}}{\sum_{i=1}^{n} m_{i}}
\end{gathered}
$$

A projeção dos comprimentos $d$ e $b$ na Figura 13 podem ser obtidos a partir das Equações (23) a (26). Por meio delas é possível chegar às equações que descrevem as componentes da força exercida no solo pelo bípede no plano sagital descritas pelas Equações (27) e (28).

$$
\begin{aligned}
& d_{x}=D \sin \gamma_{3}+l_{2} \sin \gamma_{2}+l_{1} \sin \gamma_{1} \\
& d_{y}=D \cos \gamma_{3}+l_{2} \cos \gamma_{2}+l_{1} \cos \gamma_{1} \\
& b_{x}=D \sin \gamma_{3}+\left(\frac{m_{3} l_{3} \sin \beta_{1}+\left(m_{4}+m_{5}\right) l_{4} \sin \beta_{2}}{m_{3}+m_{4}+m_{5}}\right) \\
& b_{y}=D \cos \gamma_{3}+\left(\frac{\left(m_{3}+m_{5}\right) l_{3} \cos \beta_{1}+m_{4} l_{4} \cos \beta_{2}}{m_{3}+m_{4}+m_{5}}\right) \\
& F_{x}=\left(\ddot{d}_{x}+\ddot{b}_{x}\right) \sum_{i=1}^{n} m_{i} \\
& F_{x}=\left(\ddot{d}_{y}+\ddot{b}_{y}-2 g\right) \sum_{i=1}^{n} m_{i}
\end{aligned}
$$


Onde $m_{i}$ é a massa do i-ésimo membro, $d_{x}$ e $d_{y}$ são as componentes do vetor comprimento do pendulo invertido, $b_{x} b_{y}$ são as componentes do vetor comprimento do pendulo $\gamma_{i}$ e $\beta_{i}$ são os i-ésimos angulos entre o eixo $y$ e os vários membros do bípede.

\subsection{Modelo de Marcha}

A passada ou ciclo de marcha é definido como sendo a duração ou o espaço do evento da perna até o mesmo evento da mesma perna no contato seguinte. Pode-se dividir o ciclo de passo em duas principais fases:

- Fase de oscilação: vai do período em que o pé deixa o contato com o solo até o momento de um novo contato pela mesma perna;

- Fase de apoio: consiste no período que vai do instante inicial do contato com o solo até o instante final do contato da mesma perna.

Estas duas fases podem ser analisadas através do conceito de deslocamento virtual e empregar sistemas de energia e trabalho como funções de coordenadas generalizadas para a obtenção de um conjunto de equações diferenciais de segunda ordem do movimento. Este método é realizado através da Lagrangeana de um sistema.

A Lagrangeana do bípede é modelada na fase de oscilação e na fase de apoio. Em ambas as fases, assumiu-se que as articulações da perna são consideradas juntas, que o comprimento dos seguimentos permanece constante durante o movimento e que as massas dos membros são concentradas no centro de gravidade.

\subsubsection{Fase de Oscilação}

Nesta fase, as coordenadas generalizadas são dadas pelos ângulos formados entre a coxa e a rela ortogonal à parte superior do corpo e entre o joelho e a mesma reta ortogonal. As massas da coxa da perna e do pé são consideradas neste momento A Figura 11 mostra como é a configuração do sistema em questão.

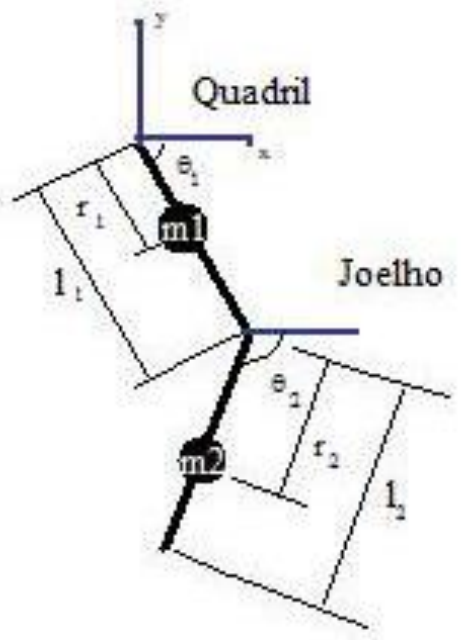

Figura 11: Configuração do sistema analisado em fase de oscilação.

Este modelo permite chegar ao sistema de equações que são agrupadas na forma matricial descritas na Equação (29). Esta equação no permite chegar às forças generalizadas do espaço das juntas.

$$
\bar{Q}_{o c}=A \ddot{q}+B \dot{q}+C q
$$


Onde $\bar{Q}_{o c}$ é o vetor de torques entre as juntas do bípede na fase de oscilação, em que $\ddot{q}, \dot{q}$ e $q$ são os vetores aceleração, velocidade e angulos em $\pi$ rad do modelo, $m_{1}$ é a massa da coxa, $m_{2}$ é são a massa da perna somada à massa pé, $r_{1}$ e $r_{2}$ são as distancias entre os elos de cada junta e o ponto do centro de massa de cada membro, $l_{1}$ e $l_{2}$ são os comprimentos de cada membro, $\theta_{1}$ e $\theta_{2}$ são os angulos ocorrentes na coxa e na perna respectivamente e $g$ é a aceleração gravitacional.

\subsubsection{Fase de Apoio}

Nesta fase, as coordenadas generalizadas compreendem-se nos ângulos formados pelos ângulos entre a reta paralela à sola do pé com a perna, coxa e a parte superior do corpo. Nesta fase o sistema sofre uma força de reação vinda do solo. As massas da perna, coxa e da região acima do quadril. A Figura 12 ilustra a configuração adotada.

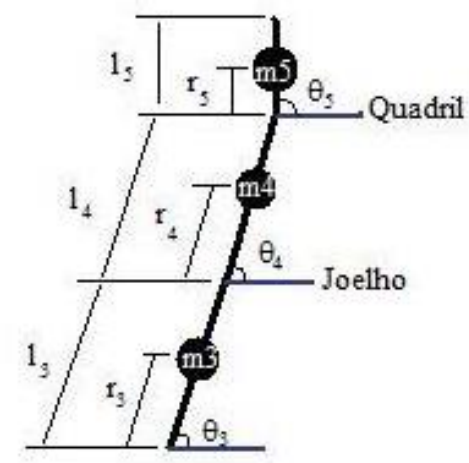

Figura 12: Configuração do sistema analisado em fase de apoio.

A partir da modelagem nesta fase e da mecânica lagrangeana, é permitido chegar ao sistema de equações cuja forma matricial é descrita pela Equação (30) com estrutura similar à Equação (31).

$$
\bar{Q}_{a p}=M \ddot{n}+N \dot{n}+O n
$$

Onde $\bar{Q}_{a p}$ é o vetor de torques entre as juntas na fase de apoio, $\ddot{q}, \dot{q}$ e $q$ são os vetores aceleração, velocidade e ângulos do modelo.

\subsection{Modelo de Orientação da Prótese}

Durante o caminhar, o monitoramento da distância e do ângulo entre a prótese e o solo ocorrerá através de uma série de sensores e receptores ultrassônicos colocados na sola do pé. Esta medição será feita através de pulsos. Na Figura 13, os receptores são representados por Rx1 e Rx2 e o emissor por Tx num espaço bidimensional.

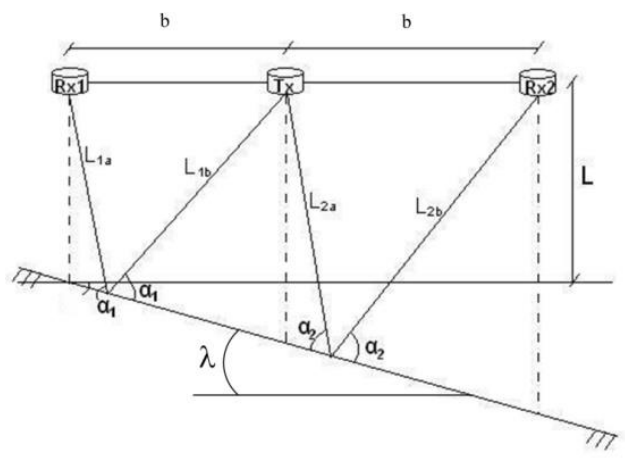

Figura 13: Representação dos sensores durante a reflexão dos pulsos. 
As medições são baseadas distância entre os pulsos emitidos (CASCÃO et al, 2005). A distância percorrida por cada um dos pulsos é dada pelas Equações (32) e (33). O espaço entre cada pulso emitido é dado pela Equação (31).

$$
\begin{aligned}
& d_{1}=\frac{2 d+2 b \tan \gamma}{\sin \alpha_{1}} \\
& d_{2}=\frac{2 d+3 b \tan \gamma}{\sin \alpha_{2}} \\
& \Delta t=\frac{2 b \sin \gamma}{(\sin \alpha) v}
\end{aligned}
$$

Onde $b$ é a distância entre os transdutores, $v$ é a velocidade do som no $a r, \alpha=\left\{\alpha_{1} ; \alpha_{2}\right\}$ é o ângulo de incidencia dos pulsos no solo, $d=\frac{\Delta t . v}{2}$ é a distancia do pé ao solo e $d_{1}$ e $d_{2}$ que podem ser escritos como $d_{1}=L_{1 a}+L_{1 b}$ e $d_{2}=L_{2 a}+L_{2 b}$ são as distancias atuais geradas pelo deslocamento angular do pé.

\subsubsection{Trajetórias da perna durante o caminhar}

Através de estudos utilizando conceitos vetoriais, procurou-se estudar o caminhar humano por meio das trajetórias de um gait que a perna pode fazer durante o caminhar. Isso possibilitaria o entendimento do comportamento do pé humano e no estudo de seus movimentos.

A priori procurou-se compreender quais as possibilidades de movimento que a perna poderia realizar em um espaço de coordenadas bidimensional. Dividiu-se a perna em coxa, perna e pé, conforme a Figura 14. Entretanto, se assumiu neste estudo apenas os movimentos da coxa e da perna para a obtenção das trajetórias.

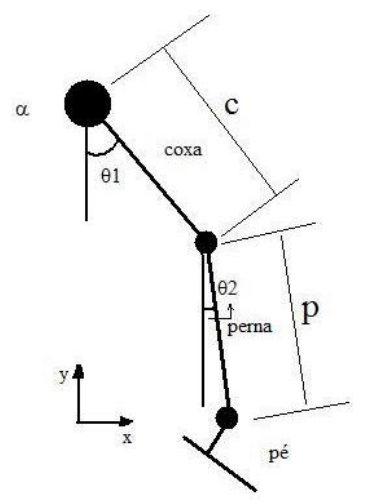

Figura 14: Configuração da perna para traçar as trajetórias da perna.

Para a obtenção das trajetórias da coxa e da perna, fixou-se a origem dos movimentos na junção da coxa com a bacia denotada na Figura 18 por $a$, mas a o referencial de origem foi instalado no ponto ao extremo da perna quando ela está ereta conforme o que foi denotado na imagem anterior.

A obtenção das fórmulas que descrevem as trajetórias foram feitas por meio de equações paramétricas a partir de relações de projeção de pontos nos eixos $x$ e $y$ e relações trigonométricas. As Equações (34) e (35) descrevem o movimento da coxa e as Equações (36) e (37) descrevem o movimento da perna de maneira paramétrica.

$C_{x}=c \cdot \sin \varphi$ 


$$
\begin{aligned}
& C_{y}=D-c \cdot \cos \varphi \\
& P_{x}=C_{x}+p \cdot \sin \alpha \\
& P_{x}=C_{y}-p \cdot \cos \alpha
\end{aligned}
$$

Onde $C_{x}$ e $C_{y}$ são as posições em $x$ e $y$ da coxa, $P_{x}$ e $P_{y}$ são as posições em $x$ e $y$ da perna, c é o comprimento da coxa, $D$ é a posição em $y$ da origem da coxa, $p$ é o comprimento da perna e $\varphi$ e $\alpha$ são os angulos qua a coxa e a perna, respectivamente, realizam com relação ao eixo $y$.

Tomou-se como função angular da perna a coxa, com respeito ao tempo, as Equações (38) e (39).

$$
\begin{aligned}
& \varphi=\rho \sin (\pi t) \\
& \alpha=\frac{(|\cos (\pi t)|+\cos (\pi t)) \cdot \rho}{2}-\varphi
\end{aligned}
$$

\subsection{Modelo Bípede em Três Dimensões}

Ao longo do desenvolvimento desta pesquisa, foram conhecidas novas ferramentas matemáticas que permitiram escrever de maneira mais eficiente e mais prática o modelo cinemático de um sistema com vários graus de liberdade. Para modelar um bípede, foi utilizado o algoritmo de Denavit-Hartenberg para relacionar vários sistemas de coordenas com um sistema fixo como origem.

Para modelar o bípede, planejou-se seus graus de liberdade de maneira similar ao robô utilizado em Ferreira, Crisóstomo e Coimbra (2003), conforme a configuração ilustrada na Figura 15. A Tabela 2 mostra os parâmetros D-H obtidos da nesta figura da perna esquerda com referência ao quadril.

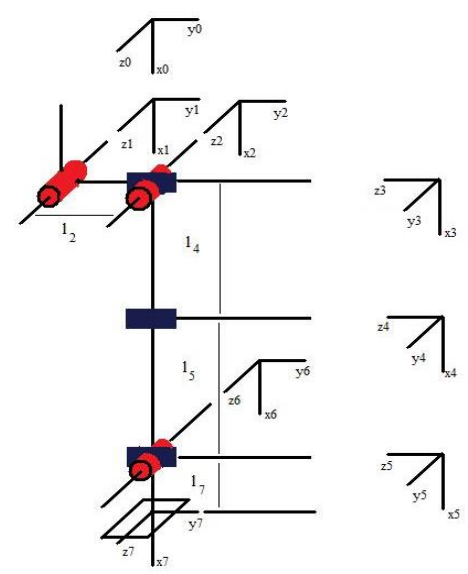

Figura 15: Modelo geométrico da perna de um bípede com referência ao quadril.

Tabela 2: Parâmetros D-H do bípede.

\begin{tabular}{ccccc}
\hline elo & $\theta_{i}$ & $\alpha_{i}$ & $l_{i}$ & $d_{i}$ \\
\hline $\mathbf{1}$ & 0 & 0 & $l_{1}$ & 0 \\
$\mathbf{2}$ & $\operatorname{Var}+\frac{\pi}{2}$ & 0 & $\boldsymbol{l}_{2}$ & 0 \\
$\mathbf{3}$ & $\operatorname{Var}-\frac{\pi}{2}$ & $\frac{\pi}{2}$ & 0 & 0 \\
$\mathbf{4}$ & $\operatorname{Var}$ & 0 & $l_{4}$ & 0 \\
$\mathbf{5}$ & $\operatorname{Var}$ & 0 & $l_{5}$ & 0 \\
$\mathbf{6}$ & $\operatorname{Var}$ & $\frac{\pi}{2}$ & 0 & 0 \\
$\mathbf{7}$ & $\operatorname{Var}$ & 0 & $l_{7}$ & 0 \\
\hline
\end{tabular}


Em que $\theta_{i}$ é o ângulo de cada um dos i-ésimos elos, $\alpha_{i}$ é o ângulo de torção de uma junta a outra, $l_{i}$ é o comprimento entre cada junta e $d_{i}$ é o comprimento ao longo do eixo da junta.

A partir destes dados, pode-se modelar a posição de cada perna a partir de matrizes de transformação. A perna esquerda do bípede foi modelada da conforme (40), (41) e (42). O modelo da perna direita pode ser obtido trocando o sinal de $l_{1}$. Onde $\bar{C}, \bar{P}$ e $\bar{T}$ são o vetor de localização coxa, perna e pé respectivamente.

$$
\begin{aligned}
& \bar{C}=B_{1}^{0} \cdot B_{2}^{1} \cdot B_{3}^{0} \cdot B_{4}^{3} \bar{r} \\
& \bar{P}=B_{1}^{0} \cdot B_{2}^{1} \cdot B_{3}^{0} B_{4}^{3} \cdot B_{5}^{4} \cdot \bar{r} \\
& \bar{T}=B_{1}^{0} \cdot B_{2}^{1} \cdot B_{3}^{0} \cdot B_{4}^{3} \cdot B_{5}^{4} \cdot B_{6}^{5} \cdot B_{7}^{6} \cdot \bar{r}
\end{aligned}
$$

Com este modelo, é possível simular a maior parte dos movimentos possíveis de um bípede humano possuindo apenas o padrão de marcha executado durante o caminhar. Assim, é possível obter relações de força e velocidade de acordo com o tipo de caminhar.

\section{RESULTADOS EXPERIMENTAIS}

\subsection{Projeto de um Modelo de Prótese}

Após estudos sobre as características anatômicas do pé humano e na intenção de projetar uma prótese que possua características anatômicas similares as do pé humano, projetou-se uma prótese robótica baseada na estrutura de um pé humanoide.

Para se estudar de maneira pratica sobre a estrutura do pé durante o movimento, foi construído um protótipo utilizando eletrodos de solda elétrica. Este protótipo é constituído de uma estrutura rígida que poderia abranger a região calcânea, os segmentos similares aos metatarsos e estruturas que visão simular os dedos. A Figura 16-a) mostra o protótipo construído.

A adaptação do protótipo ao solo se dá por meio dos dedos que foram construídos para se acomodarem ao solo do mesmo modo que os dedos do pé humano em mesmas condições. Para isto, foram implementadas estruturas análogas aos tendões do pé humano que fazem o papel de manter os dedos sempre flexionados para frente. Na Figura 16-b), pode-se visualizar o comportamento do protótipo submetido a uma força que dobra os dedos para cima. A Figura 16-c) mostra a adaptação do protótipo ao solo quando submetido a uma irregularidade na região dos dedos.

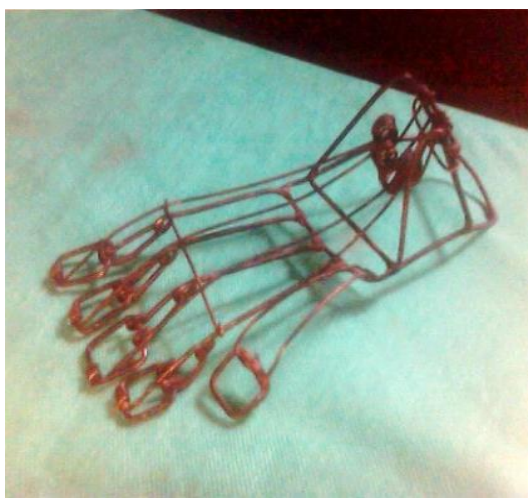

a)

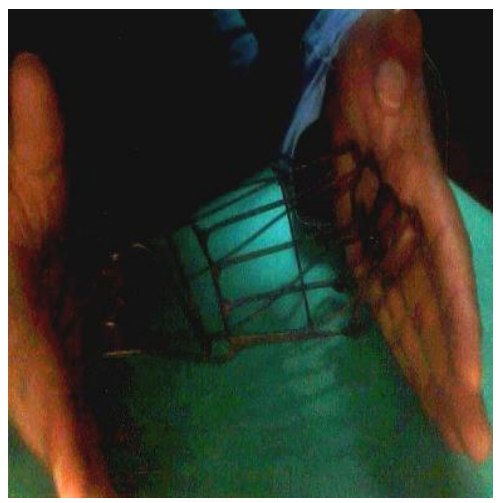

b)

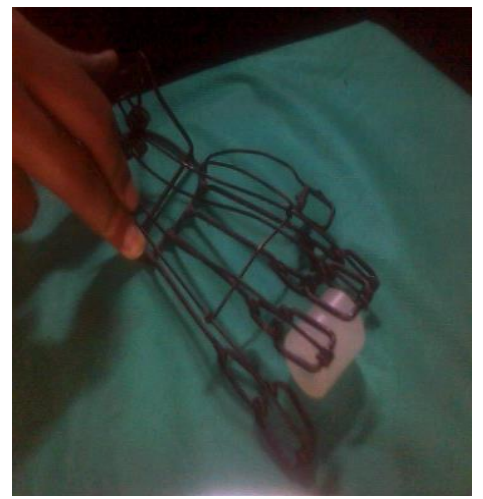

C)

Figura 16: Protótipo implementado - a) Visualização superior; b) Submetido a uma força e c) Adaptação ao solo quando submetido a uma irregularidade na região dos dedos. Fonte: (Autoria Própria) 
A partir deste modelo, foi projetada uma versão mais robusta com características similares. Procurou-se reduzir o número de modo que apenas três exercessem o papel dos cinco. Então, utilizando de uma ferramenta CAD, projetou-se uma versão mais realista da prótese que este trabalho propõe. $O$ desenho foi desenvolvido através do software CATIA ${ }^{\circ}$ V5 R19 e é ilustrado pela Figura 17.

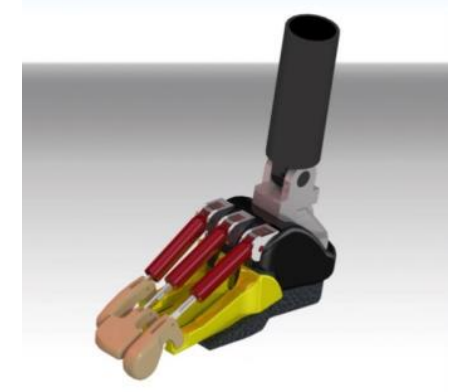

Figura 17: Modelo desenvolvido em uma ferramenta CAD.

Este modelo foi projetado para se acomodar ao solo e absorver parte da força peso do usuário se deformando parcialmente no arco do plano sagital do pé. Os êmbolos localizados na parte de cima da prótese servem de tendões para manter os dedos do pé sempre na mesma posição e se deformarem quando exercida uma força e permitindo um melhor apoio durante o caminhar.

\subsection{Simulações em Matlab ${ }^{\circledR}$}

Através do desenvolvimento deste trabalho, foi possível obter alguns ambientes de simulação que nos permitem visualizar a aplicação dos modelos propostos a fim de se obter dados ou simplesmente possuir uma estrutura a ser controlada para a prótese robótica.

A estrutura de cada simulação foi construída utilizando como ferramenta um ambiente computacional de linguagem matemática com recurso de gráficos. A ferramenta utilizada foi o Matlab ${ }^{\bullet}$ R2008. As técnicas de construção de modelos foram feitas através de técnicas da álgebra matricial para a descrição de polígonos no espaço tridimensional que são a base da computação gráfica (anton).

Para verificar o comportamento da prótese robótica em função dos ângulos que poderiam ser posicionados os acionadores, construiu-se um modelo de pé virtual em que o sistema referencial da origem se localiza no tornozelo. A Figura 18 ilustra os momentos de simulação da cinemática do pé onde foram adicionados $0^{\circ}$ e $0^{\circ} \mathrm{em} \mathrm{a}, 15^{\circ}$ e $0^{\circ} \mathrm{em} \mathrm{b}, 0$ e $30^{\circ}$ em ce $-15^{\circ}$ e $30^{\circ}$ em d em $\theta_{1}$ e $\theta_{2}$ respectivamente, onde $\theta_{1}$ representa o ângulo que o pé realiza no plano frontal e $\theta_{2}$ é o ângulo realizado no plano sagital.

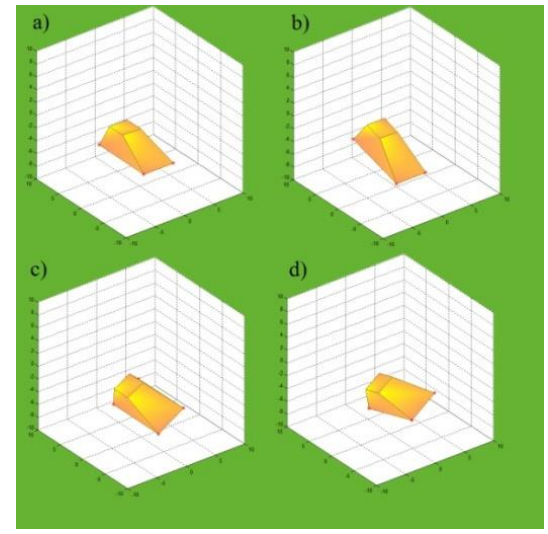

Figura 18: Simulação da prótese. 0 modelo mostra como o pé irá se portar em função dos ângulos adicionados.

Como visto anteriormente, o modelo diferencial nos permitirá obter os incrementos angulares ou lineares da prótese através da jacobiana do pé. Além disso, o modelo diferencial tem grande importância 
na malha de controle de posição da prótese. A simulação diferencial aqui implementada consiste na obtenção dos ângulos por meio da diferencial do vetor posição, que remete a um ponto qualquer na sola do pé, onde a atualização da posição se dá pela Equação (13). A Figura 19-a) apresenta uma trajetória gerada e o resultado obtido é o valor dos ângulos $\theta_{1}$ e $\theta_{2}$ do pé que descrevem este movimento. Este resultado é ilustrado pela Figura 19-b). A equação que descreve o vetor posição nesta simulação é descrita pela Equação (43).

$$
\bar{p}=\left[\begin{array}{c}
\cos (k t) \\
0 \\
\sin (k t)
\end{array}\right]
$$

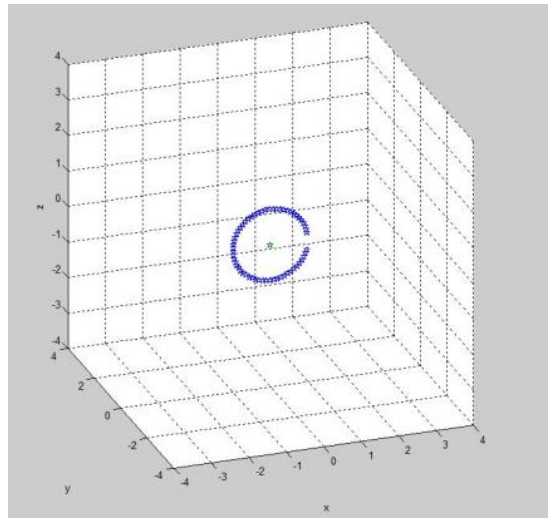

a)

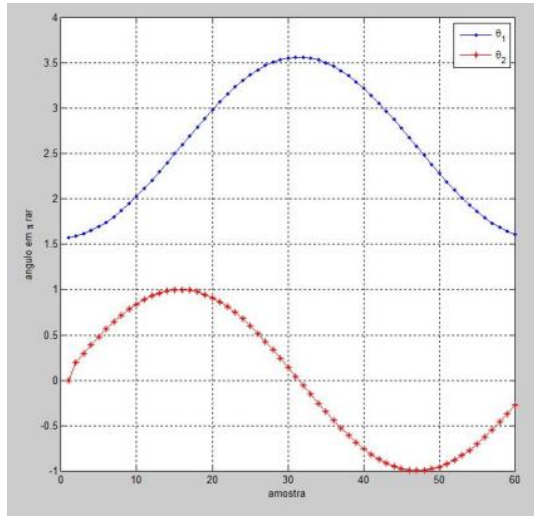

b)

Figura 19. Resultados obtidos no Matlab - a) Ângulos obtidos através dos incrementos lineares sofridos; b) Trajetória gerada nesta simulação. Para este referencial, a sola do pé seria um plano normal ao plano $(x, y)$. Fonte: (Autoria Própria)

Utilizando dos mesmos princípios das simulações anteriores, implementou-se um modelo que pudesse devolver as distâncias que seriam obtidas por sensores ultrassom localizados na sola do pé durante a trajetória do caminhar. A Figura 32 mostra um instante de simulação do pé em uma trajetória simular parametrizada nas Equações (44), (45), (46). A Figura 20 apresenta o resultado da medição de quatro sensores com um ruído de $3 \mathrm{~mm}$.

$$
\begin{aligned}
& X=0 \\
& Y=50 \cos (k t) \\
& Z=10 \sin (k t)
\end{aligned}
$$

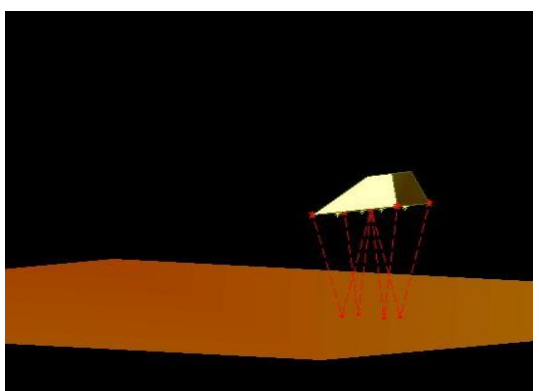

a)

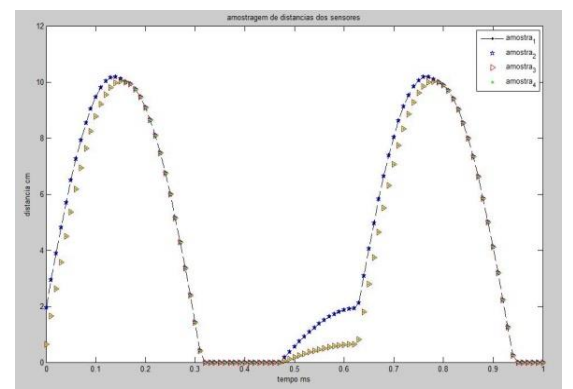

b)

Figura 20: Medição das distâncias - a) Instante de simulação do modelo de orientação; b) Medições das distâncias médias entre o emissor e cada receptor. Fonte: (Autoria Própria)

Um modelo bípede também foi implementado em um ambiente virtual. Este modelo possui $12 \mathrm{GL}$ 's e é constituído de pés, perna, coxa e quadril. Além disso, existe uma massa virtual acima do quadril que 
substitui a massa da região superior do corpo. Ele é capaz de simular um caminhar com características similares as do ser humano. Como resultado da simulação, são apresentados os torques obtidos em cada junta. A Figura 21-a) mostra o ambiente de simulação em questão e a Figura 21-b) mostra os torques obtidos em cada junta na fase de oscilação e na fase de apoio. A Tabela 3 apresenta as configurações de massa e dimensões do bípede.

Tabela 3 - Configuração das dimensões e massa do bípede simulado.

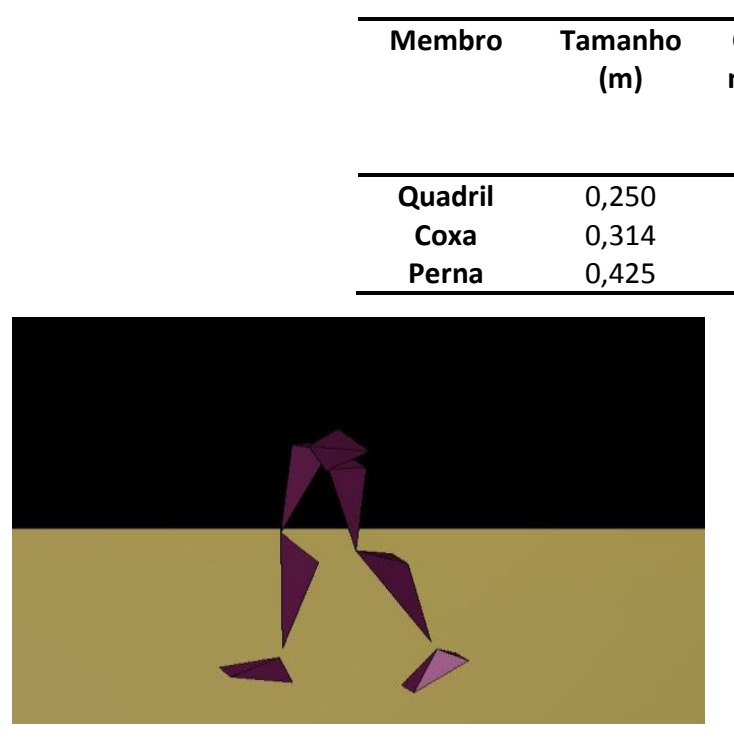

a)

\begin{tabular}{ccc}
$\begin{array}{c}\text { Centro de } \\
\text { massa (os- } \\
\text { cila- } \\
\text { ção)(m) }\end{array}$ & $\begin{array}{c}\text { Centro de } \\
\text { massa } \\
\text { (apoio)(m) }\end{array}$ & $\begin{array}{c}\text { Massa } \\
\text { (kg) }\end{array}$ \\
\hline- & 0,250 & 38,44 \\
0,136 & 0,178 & 5,67 \\
0,213 & 0,241 & 2,64 \\
\hline
\end{tabular}

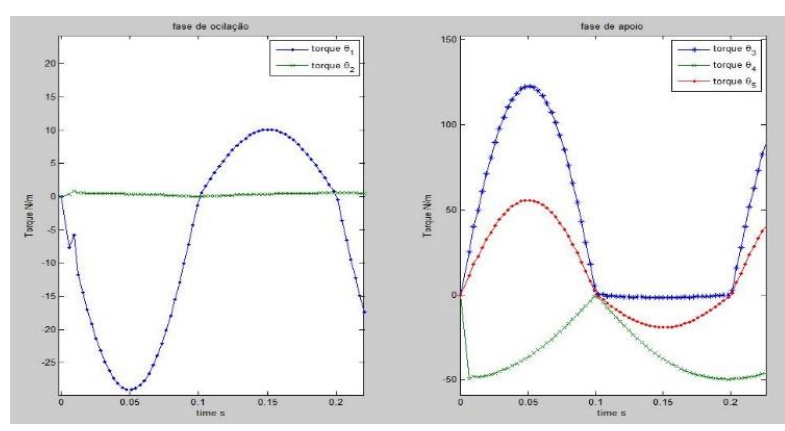

b)

Figura 21 - Modelo bípede implementado em ambiente virtual - a) Instante de simulação do modelo bípede implementado; b) Amostras dos torques em cada junta na fase de oscilação (à esquerda) e na fase de apoio (à direita). Fonte: (Autoria Própria)

Ainda por este modelo, comparou-se o torque do pé em função do ângulo no plano sagital obtido com o medido em experimentos de laboratório apresentados em (artigo do torque em função do angulo). Isso permite inferir uma diferença entre os dados adquiridos em simulação e os extraídos de um caminhar real, que pode ser causado pela incompatibilidade entre o caminhar do bípede simulado com o caminhar humano e a massa corporal entre elas, entretanto, nota-se uma relativa similaridade no comportamento do torque em relação ao ângulo. A Figura 22 mostra os dois gráficos do torque do pé em função do ângulo no plano sagital.
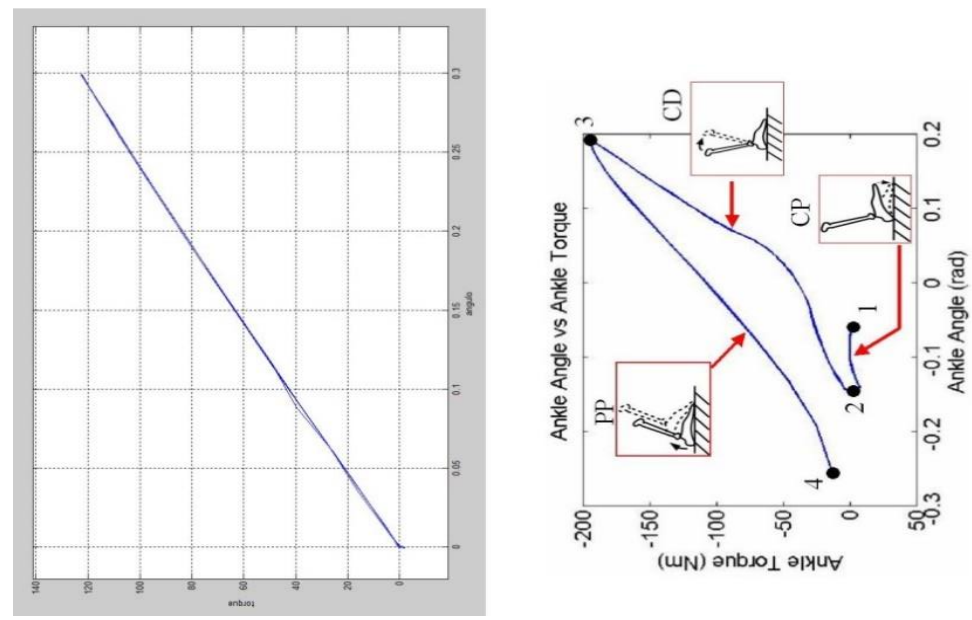

Figura 22: Comparação entre o comportamento do torque do pé obtido neste trabalho (esquerda) e em laboratório (direita) (AU, DILWORTH e HERR, 2006). Há uma verossimilhança com relação ao comportamento dos troques cujas discrepâncias podem estar relacionadas às diferenças entre os gaits e as dimensões entre cada experimento. 
As simulações puderam mostrar que os modelos propostos atendem de maneira satisfatória as condições em que foram submetidos. $O$ modelo de orientação do pé pode servir de parâmetro para o ajuste de posição no modelo cinemático onde as medições obtidas avaliarão se a prótese estará em fase de oscilação ou de apoio. No caso da fase de apoio, o comportamento do torque aqui obtido poderá servir de norma para o a força exercida pelos acionadores.

\section{CONCLUSÃO}

O modelo cinemático aqui implementado é uma estrutura e tem grande importância para o controle da prótese uma vez que toda a dinâmica inserida no pé afetará diretamente seu comportamento e sua orientação, onde os sensores ultrassom que serão implementados podem permitir relacionar o sistema de coordenadas da prótese com o sistema de coordenadas do meio externo. Toda dinâmica do caminhar relacionadas ao ZMP já é algo intrínseco no ser humano uma vez que seu equilíbrio durante o caminhar depende das forças que o impulsionam contra as que o impedem de se locomover. Nisto, o modelo de pêndulo invertido pode fornecer estas forças. Com o modelo de marcha, pode-se perceber que a evolução dos torques na fase de oscilação e de apoio podem contribuir para o controle responsável pelo incremento de forças na prótese a fim de tornar a dinâmica do caminhar mais realista e permitir uma melhor interação entre o pé e o usuário. Por meio dos estudos realizados, também foi possível compreender as características antropomórficas do pé e elaborar um protótipo com capacidade de se acomodar ao solo e, possivelmente, permitir um melhor apoio ao pisar nos mais diversos tipos de terreno.

Espera-se com o que foi desenvolvido, o modelo do comportamento do pé obtido possa servir para futuros estudos relacionados a próteses robóticas e somar conhecimentos para a biomecânica dos membros inferiores.

\section{REFERÊNCIAS BIBLIOGRÁFICAS}

1. ALVES, Eduardo S. "Implementação de uma Simulação para Estimação de Postura com Relação ao Solo de uma Prótese Robótica". Universidade de Brasília - Departamento de Engenharia Elétrica. Monografia de graduação, 2009.

2. ANTON, Howard; RORRES, Chris. Álgebra linear com aplicações. Bookman, 2001.

3. AU, Samuel K.; DILWORTH, Peter; HERR, Hugh. An ankle-foot emulation system for the study of human walking biomechanics. In: Robotics and Automation, 2006. ICRA 2006. Proceedings 2006 IEEE International Conference on. IEEE, 2006. p. 2939-2945.

4. BLAYA, Joaquin A.; HERR, Hugh. Adaptive control of a variable-impedance ankle-foot orthosis to assist drop-foot gait. Neural Systems and Rehabilitation Engineering, IEEE Transactions on, v. 12, n. 1, p. 2431, 2004.

5. BRASIL, D. A. Controle de orientação do pé de uma prótese robótica para amputados acima do joelho. Monografia de graduação, p. 13, 2008.

6. CASCÃO JR, Carlos Alberto et al. Estudo e desenvolvimento de uma prótese ativa de perna comandada por sinais eletromiográficos. VII Simpósio Brasileiro de Automação Inteligente, 2005.

7. CASSEMIRO, Edna Rodrigues. Metodologia para desenvolvimento de dispositivos biomecânicos para aplicação em próteses antropomórficas. 2002.

8. CRAIG, John J. Introduction to robotics: mechanics and control. Upper Saddle River: Pearson Prentice Hall, 2005.

9. FERREIRA, J. P.; CRISÓSTOMO, M.; COIMBRA, António P. Decreasing the dynamic stability calculation 
time of a Biped Robot. Jornadas Luso-Espanholas, v. 1, p. 3103-3108, 2003.

10. BORGES FILHO, Roberto; ALMEIDA, Sérgio JA. Locomoção humana: diretrizes terapêuticas com base nos conhecimentos evolutivos. Arq. ciênc. saúde, v. 11, n. 2, p. 72-75, 2004.

11. GOMES, M. Alberto. Algoritmo de adaptação do padrão de marcha utilizando redes neurais. Universidade de São Paulo - Escola de engenharia de São Carlos. Trabalho de Conclusão de Curso, 2009.

12. HEINEN, Milton Roberto; OSÓRIO, Fernando Santos. ROBÔS BÍPEDES: O ESTADO DA ARTE. 2001.

13. HIRUKAWA, Hirohisa et al. A universal stability criterion of the foot contact of legged robots-adios zmp. In: Robotics and Automation, 2006. ICRA 2006. Proceedings 2006 IEEE International Conference on. IEEE, 2006. p. 1976-1983.

14. HUANG, Qiang et al. A high stability, smooth walking pattern for a biped robot. In: Robotics and Automation, 1999. Proceedings. 1999 IEEE International Conference on. IEEE, 1999. p. 65-71.

15. JIN, Dewen et al. An intelligent above-knee prosthesis with EMG-based terrain identification. In: Systems, Man, and Cybernetics, 2000 IEEE International Conference on. IEEE, 2000. p. 1859-1864.

16. LEITHOLD, Louis. O cálculo com geometria analítica. 3a Edição. Editora HARBRA. São Paulo, v. 2, 1994.

17. NADALIN, E. Z. Determinação da Força Peso, a Partir do Impacto da Pisadas, Utilizando um Sensor Piezoelétrico. Universidade Estadual de Campinas - Faculdade de Engenharia Elétrica e de Computação. Monografia de Graduação, 2010.

18. PARK, Jong H.; KIM, Kyoung D. Biped robot walking using gravity-compensated inverted pendulum mode and computed torque control. In:Robotics and Automation, 1998. Proceedings. 1998 IEEE International Conference on. IEEE, 1998. p. 3528-3533.

19. POPOVIC, Mako; ENGLEHART, Amy. Angular momentum primitives for human walking: biomechanics and control. In: Intelligent Robots and Systems, 2004.(IROS 2004). Proceedings. 2004 IEEE/RSJ International Conference on. IEEE, 2004. p. 1685-1691.

20. ROSA, Suélia de S. Rodrigues Fleury et al. MATHEMATICAL MODELING OF PASSIVE DIABETIC STEP. VII Congresso Nacional de Engenharia Mecânica. Uberlândia - MG - Brasil, 2014.

21. SANTOS, Vítor MF. Robótica Industrial. Universidade de Aveito - Departamento de Engenharia Mecânica, 2004.

22. WAVRZYNCZAK, Hione Cleder; ULBRICHT, Gerson; TEIXEIRA, Edson Sidnei Maciel. MODELO MATEMÁTICO PARA CORTES DE BARRAS DE AÇO NO PROCESSO DE FABRICAÇÃO DE TRIÂNGULOS. HOLOS, v. 8, p. 252-261, 2016. 